\title{
What Science Cannot Do: The Question Concerning Science and Heidegger
}

\author{
Bowen Zha \\ Faculty of Philosophy, Kyushu University, Fukuoka, Japan \\ Email: zhb.bowen.030@s.kyushu-u.ac.jp
}

How to cite this paper: Zha, B. W. (2022). What Science Cannot Do: The Question Concerning Science and Heidegger. Open Journal of Philosophy, 12, 69-85. https://doi.org/10.4236/ojpp.2022.121005

Received: January 19, 2022

Accepted: February 14, 2022

Published: February 17, 2022

Copyright (c) 2022 by author(s) and Scientific Research Publishing Inc. This work is licensed under the Creative Commons Attribution International License (CC BY 4.0).

http://creativecommons.org/licenses/by/4.0/ (c) (i) Open Access

\begin{abstract}
This paper revisits Heidegger's views on science and examines the relationship between science and thinking. Science, dominated by metaphysical subject-object thinking, understands beings (Seiende) as an object while forgetting the Being (Sein), and for Heidegger, this lack of understanding of Being is the lynchpin to his perception of modern science. This paper re-examines Heidegger's challenge and concludes that while science ignores Being, Heidegger's assessment of science is not a critique of science per se, but rather a critique of the danger the scientific way of thinking poses to our life world. It suggests that our unrestricted use of scientific thinking makes the meaning of Being in our own lifeworld become lost. What Heidegger implies is not that "science does not think," but that human beings who living in the metaphysical and scientifical thinking do not think.
\end{abstract}

\section{Keywords}

Heidegger, Science, Ontology, Metaphysics, Being, Thinking

\section{Introduction}

Heidegger's study of modern science and technology is still very influential today, and his famous comment, "Science does not think." (Heidegger, 1993: p. 374), has been given different reflections by many researchers. Aaron Wendland considers Heidegger's consideration of science as a provocative critique ${ }^{1}$. Furthermore, Bunge accuses this comment as incomprehensible, irrational, and an attack on science ${ }^{2}$. To illustrate Heidegger's assertion about science, and thus to ${ }^{1}$ Cf. Wendland 2019, 282: "Heidegger provocatively says that: science does not think."

2"[Heidegger] was a crafty man who took advantage of the German academic tradition for which the incomprehensible is profound. And, of course, he adopted irrationalism and attacked science because the more stupid people are, the better one can manipulate them from above." (Ignacio Vidal-Folch 2008: 188, cited in Belgrano, 2021). 
explain the problem of Heidegger's critique of and attitude toward sciencetechnology, I begin this paper by describing Heidegger's understanding of the concept of science, and the metaphysical foundations of science. In the second section, to clarify the reasons for Heidegger's attitude against science, I will interpret Heidegger's central concept, namely the meaning of Being, which is the starting point for Heidegger's "anti-science" assertion. In the third section, starting from the relationship between science and thinking, I argue that the question of "thinking" is always forgotten. In the end, I conclude with a new reading of Heidegger's "anti-scientific" attitude.

Heidegger's assertion is neither negative, nor critical, but a neutral statement. The establishment of science does not need the meaning of being to come into view, or rather it is the absence of this meaning of Being that allows science to progress. For human beings, although science cannot think about Being, science does not actually have to understand Being. It is not science itself that Heidegger criticizes, but the violation of our living world by the metaphysical thinking of science. The conclusion is that scientific thinking is neutral, and while it is true that from Heidegger's point of view he cannot understand Being, it is this lack of existential understanding that allows science to evolve. We do not need to be wary of science itself, but the unrestricted introduction of scientific thinking into our world to influence our understanding of Being.

\section{Modern Science and Metaphysics}

\subsection{Science and Mathematical Character}

Let us start the question of what the word "science" means for Heidegger. Heidegger himself used the word "science," "Wissenschaft," throughout his writing to refer to physics, but in the 1950s he also referred to psychiatry, historiography, and philology as Wissenschaften. Thus, at different stages in the development of Heidegger's thought, his "Wissenschaft" seems to imply fundamentally different areas of human inquiry and knowledge.

Nevertheless, for Heidegger, physics is typical of what he calls "science", especially Newtonian physics, which he considers to be "modern science". Or, more precisely, for Heidegger, although "science" does not only mean physics, Heidegger grasps the essence of modern science by contrasting Aristotlelian to Newtonian physics. In other words, the method of using Mathematical Character to grasp the being as an object, as opposed to the Aristotelian physics, is the essence of modern science. This focus may be reinforced by the central role that physics plays in Heidegger's reading of the ancient Greeks and the particular influence of Aristotle.

What Heidegger considered science, as distinguished from the Aristotelian physics and the medieval concept of science, he believed that beginning with Newton and Galileo, science was influenced by metaphysics and became modern science, and the fundamental characteristic of modern science is mathematical. This Mathematical Character does not mean that modern science employs ma- 
thematical methods, but "that basic stance toward things in which we take them up [vor-nehmen] at the behest of that as which they already are, must, and should be given to us." (Heidegger, 2018: p. 51).

Or, to put it another way, the ground for the Mathematical Character as the essence of modern science does not lie within the methodological character of using mathematical methods or formulas to perform calculations, but rather in the fact that the methodological tool that is mathematics can function only if we start from the premise that beings are already understood metaphysically and mathematically, which "is a projection of the thingness of things that, as it were, leaps over [hinwegspringender]." (Heidegger, 2018: p. 62). Therefore, "that mathematics, and indeed of a particular stamp, could come into play and had to do so, is the consequence of mathematical projection." (Heidegger, 2018: p. 63).

Thus, mathematical character does not refer directly to the discipline of mathematics, but to a mode of thinking that transforms the actual being into an abstraction. It is from this mode of thinking that the discipline of mathematics arose and the foundation of modern science was laid.

When we refer to disciplines such as physics or chemistry, it is clear that the development of these disciplines requires the development of mathematics as a basis, as when we need mathematical laws such as calculus to predict the trajectories of stars, or the state of quanta. But this does not only mean that a discipline like mathematics is a prerequisite for the development of modern science, but also, and more importantly, that it is the way we use mathematical and metaphysical thinking, to understand how beings and the world appear, that is the essence of mathematics and modern science.

Now let us focus on how Heidegger grasps the concept of modern science by comparing Aristotle and science after Newton. Heidegger believes there is a fundamental difference between the natural experience of ancient science and that of modern science, but this difference does not lie in the latter's emphasis on facts and concepts. Since Aristotle and Newton, both valued the observation of empirical facts. "On each side, in both ancient and modern science, we find a handling of both facts and concepts, but the mode and manner in which facts are conceived and concepts established prove decisive." (Heidegger, 2018: p. 45).

Aristotle put forward the theory of "natural body" and "natural motion" by connecting the body and the place as "how a body moves itself, i.e., how it relates itself to place and to which place it relates itself-all this has its ground in the body itself." (Heidegger, 2018: p. 57). Aristotle believed that every body on the earth has its natural place, and if a body leaves its natural place, it will try to return and undergo natural motion. The motion away from the natural place is not natural motion, but requires the continuous contact action of external forces. Some bodies are purely propelled by external forces, while others have an internal propulsion. There is always a ruling and active element in any synthesis. According to Heidegger's summary, the core of Aristotelian physics is: "the basis of natural motion lies in the nature of the body itself, in its essence, i.e., its most authentic being." (Heidegger, 2018: p. 58). 
In contrast, Heidegger analyzes modern science using Newton's first law, and he gives a simplified formulation of Newton's first law: "left to itself, every body moves itself uniformly in a straight line.” (Heidegger, 2018: p. 59). In Heidegger's view, whereas Aristotelian physics explains motion in terms of the authentic being, in Newtonian kinematics the authentic, the priority of heavenly bodies, circular motion, natural places, etc., disappears and is prescribed only in quantitative terms. As a result, the way modern science investigates nature has changed. In the words of Heidegger:

It should only have become visible that and how all essential alterations are co-posited in the positing of [Newton's] first principle of motion. These alterations are all linked together and grounded uniformly in the new basic position, which comes to expression in this first principle and that we call mathematical. (Heidegger, 2018: p. 60).

According to Heidegger, the difference between Aristotle and Newtonian science lies in the "basic position of mathematics" of Newtonian science, that is, the "Mathematical Character" of Newtonian science. Mathematical projection, as the root of modern science, means that although Newton and Galileo are thinking something in relation to the same appearance of body motion as Aristotle, the explanations they gave about where the essence of body and the nature of its motion are located are completely different. Aristotle's perspective is rooted in the nature of the body itself, in its essence, i.e., its most authentic being, while Newton and Galileo rooted it in the mathematical projection, in which "[h]ow they show themselves is prescribed by projection...; it consequently also determines the mode of receiving and investigating what shows itself, experience, the experiri." (Heidegger, 2018: p. 63).

In this way, Heidegger elucidates this crucial point, that "to what extent, and in what way the basic trait of modern thought and knowledge is mathematical in the authentic sense." (Heidegger, 2018: p. 52). The answer is, because modern science has first drawn up the basic outline of nature by mathematical projection, and this prior specification of things is the axiom. The axiom is the grasping-in-advance of beings (prior projection), which gives the measure for delimiting the scope of science, i.e., what presents itself in this outline and becomes a fact. This prior projection requires a corresponding way of dealing with things, and thus prescribes experience, and therefore the way of exploring nature that makes experimentation modern, and modern science "modern," is mathematical projection.

\subsection{Metaphysics and Ego Cogito}

From the above analysis we can conclude that in Heidegger's view, science in the sense of the ancient Greeks is based on descriptions of authentic being. During Newton's time, the Mathematical became the basis for this description of beings. The key point is the shift in the basic conception of things, from the ancient Greek nature of the body to mathematical projection. By analyzing the scientific 
method, Heidegger meditates on the foundations of our modern worldview, that is, he reduces science to a method of explaining how humans view the world, and a way of explaining what the beings encountered and revealed by humans as Being-in-the-World are. In other words, both Aristotelian and Newtonian sciences have a common purpose, that purpose being devised from a philosophical attitude through which humans interprets the world and the beings in it.

The modern scientific method implies that the scientists see themselves as Subject and the beings they deal with in the research as Objects(Gegenstand) in front of (gegen-, against) them. But remember that this very relationship between subject (scientist) and object (beings) is only possible through a prior projection of the objective position within research, and only to the extent that the object conforms to this projected position does it become an object. In other words, a priori projection filters out every element of the beings that makes it its own appearing, except that aspect which makes it the object of scientific approach (just like the laws of motion). Only when the phenomenon under interrogation is reduced to its pure object character (its objectivity) can the researcher proceed to the task of research, that is, the verification of the mathematical projection.

From this, we can conclude that the modern scientific approach presupposes a metaphysical position that the beings encountered in the world are only objects of the subject (humans). And since modern science, modern mathematics, and modern metaphysics all share a common position, the Mathematical, Heidegger is in fact critiquing the metaphysical position implicit in the modern scientific attitude, rather than finding fault with the scientific attitude itself.

This metaphysical position, in which every being (Seiend) is conceived as a subject or an object (the object of a subject), is what Heidegger called "subjectivism" since the moment when René Descartes pointed out "cogito ergo sum", "I think therefore I am". The modern scientific attitude itself is just a result of Cartesian subjectivism.

Why Descartes' ego cogito so influential in modern science? For modern science needs an absolute and eternal foundation of knowledge beyond nature (meta ta physika, lit. "after the Physics"), and Descartes provides that foundation, namely, to discover a new and absolute foundation (fundamentum absolutum) for knowledge. Descartes ruled out the Aristotelian basis of the nature of things. Only by excluding the objects in nature from the foundation of knowledge can the premises of all knowledge be based on one absolute foundation, that is, the mathematical is set as an absolute ground, and a foundation corresponding to this absolute ground is sought for all knowledge by doubting everything, i.e., cogito, "so the 'I' or human subjectivity was declared the center of thought. The modern era's standpoint of the I and its subjectivism sprang forth from this." (Heidegger, 2018: p. 67).

It is the result of this Cartesian starting point that is important for science. For Descartes, the Being of the ego is demonstrated in the act of thinking, and for the first time in the history of thought it is seen as a subjectum, something that is 
thrown below, or better yet (according to the meaning of the Greek hypokeimenon) "lies below" everything else. In this case, it is the basis of all knowledge. In other words, the self is aware of its own thingness and is a subject for the very reason that it is the absolute foundation of all knowledge. But if we go one step further, we would see that everything that does not belong to the thinking subject becomes what the ego-subject thinks about, is brought up, and becomes an object, an "object" of thinking. The object becomes thinkable only if it is found by the subject, because without this foundation, certainty (knowing that we know) is not possible. The result is that, in this new perspective, everything that exists, including the self itself, becomes either a subject of thought or an object of thought.

Until Descartes, everything on hand for itself had been counted as "subject"; but now the "I" has become the preeminent subject, hence that in relation to which the remaining things first come to be determined as such. Because-mathematically-they first receive their thingness by way of the grounding relation to the highest principle and its "subject" (the I), things are essentially what stand as other in relation to the "subject," and lie over and against the subject as objectum. Things themselves become "objects." (Heidegger, 2018: p. 72).

Thus, we can see why methods of modern science might be considered the result of Cartesian subjectivism. The rigor of the research procedure is based on the researcher's more fundamental quest for certainty, to know that researcher knows. The correlation of projection and verification is nothing but the expression in the laboratory world of the fundamental paradigm of the subject-object relation, according to which an object is proposed to the subject to the extent that the subject proposes it to themselves and, moreover, in such a way that they can control it enough to gain certainty about it.

In such case, the world itself becomes in this new perspective a worldview as it becomes the sum total of the objects of thought, the collective objects of subject. The first consequence of Descartes' discovery of the absolute foundation of thinking in self-consciousness is that all reality is divided into subject and object. The essence of modern science here is not only disciplinary, but also becomes the common nature of human beings in modern, and this perspective becomes the key to how we see beings and how being reveals itself. This way of thinking has shaped our characteristic as modern people.

\section{Meaning and Being}

As mentioned in the previous chapter, then, scientific thinking is unable to grasp Being because mathematical and metaphysical position and perspective have long been dominated by the metaphysical subject-object opposition. The missing part of this perspective, for Heidegger, is the thinking about Being itself. That is to say that there is another dimension to the understanding of beings and the world as a whole than the metaphysical-scientific one, namely the dimension of Thinking and Being. 


\subsection{World and Meaning}

According to Heidegger, we can distinguish between two dimensions in our engagement with beings: the daily dimension, in which our everyday practices and discourses disclose the properties of things and the relations between things; and the other dimension, in which these things, properties, and relations are understood as the thingness in the whole. In Being and Time Heidegger suggests how beings are encountered in these two dimensions from the various meanings of beings disclosed in our practice: the present, the available, the existential, etc. We do experience Being as such: it is the way beings are revealed to us. And the essence of beings and how they are revealed is not determined only by the thingness as an object, but also by practice and the meaning which only is revealed in the world.

For example, when we face the Rhine itself as a being (Seiend), how it appears in the world, whether as a beautiful landscape or as a source of hydroelectric power, although there are intrinsic characteristics from itself that determine its ability to be a being that provides water power as opposed to other sources of thermal power generation (i.e., a river, at a low level, or overflowing). We can assume that the Rhine cannot be seen as a hydraulic resource based on our daily experience alone, but perhaps as a beautiful scenic river or as imagery in the poet's writing. But at the same time, the subject-object projectional thinking of modern science-technology provides the practical context of planning a certain kind of being as a resource, so that it can be revealed as a certain special essence. According to Heidegger, all these things "exist" in the same unobvious way that is evident in our behavior toward them: we experience the things around us as Bestand, the "standing-reserve" of modern technology".

What remains ambiguous in this example, however, is how to interpret two dimensions of understanding beings, rather than using a general form of everyday practice. For Heidegger, what we usually call everyday understanding is not enough here, because such understanding has long been dominated by the approach of modern science. We are unable to experience the river as standingreserve in the Rhine example, because mathematical-metaphysical-science has eliminated values and secondary qualities from reality, leaving us only with such thingness as the standing-reserve of beings from a metaphysical and mathematical view. If we are to explain the two dimensions of thinking, then, we need a phenomenological clarification of how we can experience something as something, the keys to which are within Being and Time.

Let us first briefly review some of the concepts in for understanding Being, such as "World" (Welt), "Truth" (Wahrheit), and "Meaning" (Sinn). In Being and Time, Heidegger defines "Being" as "the Being of being, then beings themselves turn out to be what is interrogated" (Heidegger, 1962: p. 26), which refers to intelligibility or the horizon of meaning. In order to experience Being, human beings, which Heidegger calls Dasein, presuppose an a priori understanding of ${ }^{3}$ C.f., Heidegger (1977: p. 16), The Question Concerning Technology and Other Essays, ff. 
Being. This definition of the human is different from the Cartesian cogito. In Descartes, the only subject, i.e. cogito, as an absolute foundation does not need any object as a premise for understanding beings, but Heidegger explains Dasein in terms of Being and meaning.

For Heidegger, what something is not grasped by our reason (intellection), but by understanding its meaning in order for it to appear as what it is, that is, in the context of a normative structure, i.e., Being-in-the-World, in which this meaning of what it should be is at work, making it something. "Meaning is that wherein the intelligibility [Verständlichkeit] of something maintains itself" (Heidegger, 1962: p. 193), and not only that, but Meaning also "signifies the 'uponwhich' of the primary projection of the understanding of Being." (Heidegger, 1962: p. 371). Although scientific theory and practice provide mathematical context, science is a methodologically developed version of a general context: grasping things through their thingness. A hammer can show itself to be a hammer in the sense of being used to build something when, and only when, it is shown to be appropriate or inappropriate according to the work to be accomplished. In other words, for Dasein, the meaning of something can only be shown by grasping its position in the context. Thus, the meaning of a thing cannot be adequately determined by reference to instrumentality alone, but lies in our ability to act (praxis) for the sake of some possibility of meaning. Only in such an action, where something tries to be revealed as something, does meaning (as opposed to materiality, instrumentality, etc.) show itself. Strictly speaking, then, "only Dasein can be meaningful or meaningless." (Heidegger, 1962: p. 193).

For example, we understand the meaning of the names for everyday things such as students, teachers, textbooks, and desks. But these names acquire their meaning only because the things so named are able to show if they are able or unable to be in a "totality of meaning" or "World" of teaching and learning, to be what they ought to be. The thingness of things does not define what things are, although it does reveal certain characteristics of things, but their meaning is not "projected" onto them. The desk in front of me is an object whose presentation is not determined by its thingness. Although its material, height, construction, etc. define its characteristics, its meaning as a desk for me is not due to its essence, but I acquire its meaning as a desk in my practice with this object. Its thingness can only determine one factor in its ability to assume its use as a desk, but the manifestation of its meaning can only be obtained by practice in the world, and thus this thing shows itself as a "desk" in the world. In other words, I can only encounter something meaningful, something that succeeds or fails, when I try to reveal something to become a desk, that is, when I search for the meaning of something. This "reveal" is what Heidegger understands as truth, the word from the Greek à $\lambda \dot{\eta} \theta \varepsilon ı \alpha$ (aletheia), i.e., "unrevealedness" (Unverborgenheit). Thus, a being is when it reveals itself, when it reveals itself in the important context that Heidegger calls "World" (Welt). The World is a meaningful space that allows Being to appear, it is the open space of the meaning of beings being revealed. 


\subsection{The Being-Meaning Dimension}

Hence in Being and Time, Heidegger presents an alternative dimension to the Cartesian subject-object dimension of the relationship between humans and beings namely, thinking about the Meaning from the perspective of Being in the World. The question, then, is how this relation between being and thinking can be critical of science and metaphysics. In what sense are the two aforementioned perspectives incompatible? In the simplest sense, because for Heidegger, the "World" is much more than a collection of subjects and objects. If everything is pressed into the category of subject and object, then something of them is forgotten, such as the depth, the beauty, the deep (non-objective) freshness of things. Being (Sein) as Heidegger understands it is this very Being of beings (including humans) that accounts for the fact that they are (Being), that which makes things reveal themselves. In short, with the emergence of Descartes' subject-object bipolarity, the Being of beings is forgotten, since for Cartesian thought,

[t]he only genuine access to them (beings) lies in knowing [Erkennen], intellectio, in the sense of the kind of knowledge [Erkenntnis] we get in mathematics and physics. Mathematical knowledge is regarded by Descartes as the one manner of apprehending beings which can always give assurance that their Being has been securely grasped. If anything measures up in its own kind of Being to the Being that is accessible in mathematical knowledge, then it is in the authentic sense. Such beings are those which always are what they are. (Heidegger, 1962: p. 128)

Meanwhile, for Heidegger, for a being to "be" means to be revealed, more precisely, to be revealed in the world. Being means that process by which Meaning and Being are revealed. Being is thus an illuminating process, rather than the thingness itself. Being is the process of re-revelation in which things become unconcealed. Moreover, the Greek word for hidden is "lethe", and the "a-" prefix serves to imply the absence of this "lethe" (concealment). That which is revealed, unconcealed, is "alethes", and the process of revealing/unconcealing is "a-letheia", truth. Then, "Being" is the process of "truth," the way we access the meaning of the beings and the things become unconcealed in the world. To inquire into the meaning of "Being," then, means to think on truth as the non-concealed process by which Meaning-Being is revealed, becomes visible, and presents itself to Dasein.

In so far as the metaphysician regards beings as beings, what the metaphysician thinks is the result of the illumination of Being, of what has been revealed. But the process of illumination is not itself what it is illuminating. Being is not a result, nor is it the object of the subject as an absolute foundation; Being requires the revealing from Dasein, just as Dasein roots in Being. But for the metaphysician, what appears is what is illuminated (i.e., beings), while Being itself, as the illuminating process, recedes from him, that is, hides itself among the illuminated beings and appears as "thingness". 
As a consequence, the metaphysician, although he sees the result of illumination, is blind to its process (i.e., "forgetting of Being", Seinsvergessenheit), because of Descartes' cogito and the mathematical as an absolute foundation, and it is this process that makes the beings he contemplates accessible to him. Because science-metaphysics rests upon the accessibility of beings, the thinking of the process of illumination is then an inquiry into the "absolute foundation" of metaphysics.

This is how Heidegger described his own work as "fundamental Ontology," but in his later work Heidegger tried to overcome metaphysics and science. It is only when the metaphysicians and scientists realize that truth is not merely a congruence between human thought and the factual situation, much less the certainty, but aletheia, which comes from the relates in the Being-Meaning unconcealed in the world and based on Dasein, the un-concealed process by which process by which life is revealed and becomes Being, that the metaphysics could be overcomed. For metaphysics, however, this process of aletheia becomes the result of the certainty of the object and loses its original meaning ${ }^{4}$.

We can therefore understand the significance of Heidegger's critique of Descartes, and that Descartes' subjectivism makes the modern scientific attitude possible in the first place. Insofar as Descartes' subjectivism and scientific attitude are based on the concept of truth as certainty, they forget truth as an un-concealed process (i.e., Being itself), which makes the object visible to the subject, brings the subject into contact with the object, establishes the "absolute foundation" and describes the horizon where the encounter between subject and object can take place. For the scientist and the metaphysician, to forget Being as Being is to reduce human into an objectivity and forget the meaningfulness of the world.

For Heidegger, thinking in terms of the history of Being (Seinsgeschichte), the establishment of Descartes' Subject is the main cause of modern nihilism. But the crux of the matter is how we should view the beings around us, from its meaning, or value. It cannot be denied that value has become a goal (perhaps an ultimate goal) of modern technology. What has value is treated as a culture because of its value, and at the same time, culture is also used as a means to create value. All this is a consequence of nihilism in the eyes of Heidegger and Nietzsche, and our lives are dominated by such kind of thinking, forgetting the meaning of things.

\section{Does Science Think?}

Let us return the original question of whether Heidegger is correct in his assertion that science does not think. Aaron Wendland suggests that science can in

"'For the main feature of the essence of truth in the modern metaphysics of Schelling and Hegel is never $\dot{\alpha} \lambda \dot{\eta} \theta \varepsilon \iota \alpha$ in the sense of unconcealedness but is certainty in the sense of certitudo, which, since Descartes, stamps the essence of veritas. Anything resembling the self-certitude of the self-conscious subject is alien to the Greeks." (Heidegger, 1992: p. 19). 
fact "think" through the framework of Kuhn's paradigm shift ${ }^{5}$. Wendland argues that there is a close similarity between a certain understanding of Being, and Kuhn's concept of "revolutionary science". But if Wendland is right that, unlike normal puzzle-solving science, revolutionary science can understand Being, i.e., the meaning of beings, then Heidegger's assertion about science is wrong, as this suggests that science operates in a way that can somehow think. In this section, I will further illustrate the intrinsic difference between science and Being by analyzing Wendland's view.

Wendland begins by pointing out that the fact that Being is the basis for understanding beings (entities) suggests a close similarity between Being and paradigm, both of which can provide context for this understanding. Wendland agrees that Heidegger's claim challenges the calculative activities typical of modern technology and thus modern science. But Wendland argues that the way to rescue us from the danger of the metaphysical computation, in Heidegger's words, Gelassenheit, through which we are released from our drive to manipulate and control nature through our objectification and mathematical representations of it, is that this openness to thinking about Being can likewise be attributed to Kuhn's paradigm ${ }^{6}$. For Heidegger, releasement induces thought about the Being of beings (entities) and thereby allows us to see aspects of reality that stand beyond the confines of our destructive self-assertion. In contrast, Wendland notes, " $(t)$ he Kuhnian equivalent of opening ourselves to the essence of technology and thinking about the being of entities is revolutionary." (Wendland, 2018: p. 290). In other words, Wendland argues that science is able to grasp the Being of beings through a paradigm shift. He means that from the point of view of overcoming the limitations imposed on us through Gelassenheit, and thus being able to see different aspects of beings, similarly, "the thinking typical of revolutionary science involves both a critical reflection on an existing paradigm and a creative attempt to come up with something new." (Wendland, 2018: p. 292). Therefore, he concluded that "the crises that induce paradigm shifts lead scientists to reflect on the foundations of their discipline and it opens them up to alternative interpretations of reality in much the same way that releasement allows us to catch sight of the essence of modern technology and thus frees us to interact with entities in a new way. Briefly, revolutionary science thinks about the being of entities in a way that normal science does not." (Wendland, 2018: p. 293).

As Wendland points out, Kuhn's revolutionary science and Heidegger's Being do have something in common in terms of their openness to interpretation, i.e., their ability to understand beings in different ways. Of course, we cannot deny the fact that with revolutionary science, paradigm shifts provide us with a richer

\footnotetext{
${ }^{5}$ This view of analogy between Being and paradigm is common among many researchers. Dreyfus proposed a way of reading Heidegger's concept of truth, namely, by analogizing the varies way of aletheia with the paradigm. See, Dreyfus (2006), Nihilism, Art, Technology, and Politics, in The Cambridge Companion to Heidegger, p.354 ff.

6“' Openness to mystery' is the way he speaks of our ability reflect upon and change our activities (DT 55). And it is precisely a critique of our current activities as well as an openness to non-reductive ways of relating to entities that can save us from the dangers of techno-science." (Wendland, 2018: p. 289)
} 
explanation of Being, while allowing us to reflect on the foundations of said science. However, Heidegger and Kuhn have fundamentally different views on the correctness and legitimacy of the different interpretations.

For Kuhn, the paradigm shift is indeed always open, but this openness is based on a search for correctness, and the aim of the shifting of the new paradigm is not so much to find a new interpretation as to find a better one. Or rather, "scientific revolutions are inaugurated by a growing sense, again often restricted to a narrow subdivision of the scientific community, that an existing paradigm has ceased to function adequately in the exploration of an aspect of nature to which that paradigm itself had previously led the way." (Kuhn, 1996: p. 92). Furthermore, Kuhn noted that, just same as the relation of Copernican to Ptolemaic astronomy, the Einsteinian dynamics and Newton's Principia are "fundamentally incompatible", to the extent that "Einstein's theory can be accepted only with the recognition that Newton's was wrong." (Kuhn, 1996: p. 98). Thus, in Kuhn's view, paradigm shifts in science are not arbitrary, but have their own intrinsic criteria: a new paradigm emerges because one "paradigm is at issue," (Kuhn, 1996: p. 94). The reason why one paradigm replaces another is intrinsically based on correctness. When one agrees with paradigm A, it is natural to reject the incompatible paradigm $B$.

However, for Heidegger, the meaning of "science" has been changing from "episteme" in ancient Greece to doctrina and scientia in the Middle Ages, to the "science" that we use currently. Scientific theories are thus just one description of "physis", i.e., how the nature revealed by Dasein, and so to Heidegger, establishing standards of knowledge in terms of correctness and precision that are then used to formulate how we should describe nature is clearly problematic. Heidegger's position is to interpret the concept of science from the perspective of how Dasein reveals beings and the world. This view can be seen as a science in a broad sense. He points out that:

Greek science was never exact, precisely because, in keeping with its essence, it could not be exact and did not need to be exact. Hence it makes no sense whatever to suppose that modern science is more exact than that of antiquity. Neither can we say that the Galilean doctrine of freely falling bodies is true and that Aristotle's teaching, that light bodies strive upward, is false; for the Greek understanding of the essence of body and place and of the relation between the two rests upon a different interpretation of beings and hence conditions a correspondingly different kind of seeing and questioning of natural events. No one would presume to maintain that Shakespeare's poetry is more advanced than that of Aeschylus. It is still more impossible to say that the modern understanding of whatever is, is more correct than that of the Greeks. (Heidegger, 1977: p. 117)

From this we can see that Heidegger's concept of science cannot be read in paradigmatic terms because the Heideggerian and Kuhnian stances are incompatible with each other. First of all, the purpose and the criteria of the two are 
different. According to Kuhn's understanding, the revolution of science and scientific paradigms ultimately has only one purpose, which is to solve the problem and find the optimal solution within the new paradigm. Thus, when considered from a problem-solving perspective, whether it is traditional science or a scientific revolution, the paradigm has the sole purpose of finding a better interpretation. And for Heidegger, "science" itself has no purpose, but is only a way of presenting being, a way of aletheia from the ancient concept of physis.

Second, the two have different approaches to the nature world. For Kuhn, scientific research always presents nature as an object, the object of subject, placed before human. This state of being placed before is an a priori necessity for the scientific researcher, i.e., the absolute foundation of knowledge.

According to Heidegger, however, science can lead a being to reveal what was not known before; science can get thingness from the beings. Here it is important to understand properly how the activity of the scientific method does not lead to a "subjective" confirmation of the object. The activity of scientific observation is characterized by the "withdrawal" of the subject in the presence of an object. What the experiment reveals about an object is revealed by the way it is already arranged. These arrangements are directed to the object under investigation from the very beginning, in such a way as to induce it to produce a particular answer to the question of how it reveals itself. For example, when we research the properties of water, we need to exclude our subjective view by arranging our investigation so as to arrive at specific conclusions about its inherent properties: its chemical formula is $\mathrm{H}_{2} \mathrm{O}$, it is an electronic insulator, and so on. But even if we know all these properties, the question of what water is still remains unanswered. When we look at the thingness of beings, the meaning of being itself is hidden.

Thus, according to Heidegger, if inquiry takes as its point of departure being as an object that is revealed to us and is interpreted by science, the foundation of knowledge, i.e., the encounter of the world between Dasein and beings, are forgotten from the very beginning. "The apprehensibility and the objectivity of a thing is grounded in the encounter of the world, but objectivity is not a presupposition for the encounter." (Heidegger, 1985: p. 190). This relationship is also inverted if things in nature are revealed as a particular thingness, then are subsequently given certain value predicates, such as "good, bad, plain, beautiful, suitable, unsuitable, and the like" (Heidegger, 1985: p. 183). Although it may seem that the value is the result of an encounter with being in the world, in reality this value is entirely a product of subjectivity. For value necessarily implies validity for a particular subject, "[w] hat is valid does not have validity because it is in itself a value; rather, a value is a value because it has validity. It has validity because it has been posited as valid." (Heidegger, 1991: p. 62). Therefore, "values 'are' only where there is reckoning, just as there are 'objects' only for 'subjects."' (Heidegger, 1991: p. 63).

In Heidegger's view, such valorization caused by this inversion has taken a 
terrible toll on modern society. When Nietzsche declared in 19th century Europe that God is dead and that all values were nothing but a form of nihilism, Heidegger heard this declaration and interpreted it in terms of Being-forgotten. If the authentic sources of beings for Dasein (i.e., the meaning and the Being) are forgotten in Cartesian subjectivism, defining these values becomes the goal of all encounters with beings, is considered as cultural values and the goal of all human activity, which, in turn, is placed at the service of the realization of human certitude as subjects. The foundations of already inverted values are forgotten, and values become foundationless goals as the mere objectivity they conceal, which is the very situation of modern society about foundationlessness realized by Nietzsche.

\section{Reflection-Science Does Not Think}

Should we require science to have the ability to think about existence? Is Heidegger actually criticizing science itself, or is he talking about the limitations of science? Is this "non-thinking" of science an advantage? The point to be made in this section is that it is not science itself that Heidegger is criticizing, and even the assertion that science does not think is not a shortcoming in Heidegger's view. What Heidegger criticizes is the fact that humans, as subjects, do not think, and instead use science to so that the meaning of their own lifeworld is forgotten.

It must first be clarified that what Heidegger challenges is scientism, not science itself, as well as the metaphysical attitude toward the world, not objectivity itself. For Heidegger, objectivity is a real possibility that emerges from the context of a structure of meaning, which itself cannot be reduced to objective "independence". Although, as pointed out in the previous section, the basis of the objectivity of things lies in the encounters in the world, for Heidegger this does not mean that the practice obtained in the world is therefore superior. For Heidegger, whether it is the "ready-to-hand" state that arises from encounters in the world, or the "presence-at-hand" state of thinking about Being in terms of reason and mathematics, they are both categories, "[a]ny cognitive determining has its existential-ontological Constitution in the state-of-mind of Being-in-theworld; but pointing this out is not to be confused with attempting to surrender science ontically to 'feeling"'. (Heidegger, 1962: p. 177). The fundamental problem is that the objectivity of science is taken as the main, if not the only, criterion of Being among modern societies.

Heidegger's phenomenology is neither the same as subjectivism nor the denial of objectivity in all senses. As Heidegger puts it, the "objectivity" of a science is given according to how it discovers life within the limits of its questioning, and therefore there is nothing "subjective" about it ${ }^{7}$. Revealing does not "create" 7“The historiological disclosure of the 'past' is based on fateful repetition, and is so far from 'subjective' that it alone guarantees the 'Objectivity' of historiology. For the Objectivity of a science is regulated primarily in terms of whether that science can confront us with the entity which belongs to it as its theme, and can bring it, uncovered in the primordiality of its Being, to our understanding." (Heidegger, 1962: p. 447). 
truth, as if it did not exist before it was discovered, but" [o]nce beings have been uncovered, they show themselves precisely as beings which beforehand already were." (Heidegger, 1962: p. 269). This "precisely" suggests a realism, but this "revealing" of the way of being in the world through Dasein is not allowed by the absolute foundation required by scientific-metaphysical intellectio.

As Heidegger points out, "[n]ature, in its objectness for modern physical science, is only one way in which what presences-which from of old has been named physis-reveals itself and sets itself in position for the refining characteristic of science." (Heidegger, 1977: p. 174). What Heidegger insists on is the diversity of ways of revealing, of which the particular way of science is only one, albeit an extremely powerful and important one. Heidegger's complaint against the scientisms is that the latter's position does not recognize the possibility of such other modes. In other words, Heidegger wants to acknowledge that what is "outside" science for humans nowadays, that is, what is beyond the scientific perspective, is demonstrated through other means of engaging and talking about the world.

In addition, if we examine Heidegger's text in depth, we will find that his approach to science is not truly critical. Following his statement about science, Heidegger added that, "[i]t (science) does not think because it can never reflect on the manner of its proceeding and its tools-does not think, namely, in the manner of the thinker. That science cannot think is not a lack but rather an advantage. That alone secures for it the possibility of engaging in a certain region of objects in the manner of research and settling itself therein." (Heidegger, 2000: p. 133).

The advantage is that science's inability to think allows it to remain neutral and does not regard creation as inherently superior or inferior to God's "ens creatum", as medieval scientific theology did. Therefore, it also means that this unconditional scientific thinking should have nothing to do with what is good or bad for humanity. Scientific knowledge does not think about any meaning, Being, or even human existence itself. If we take modern science seriously, that is, if we accept that it constructs its own objects while destroying meaning, we should also agree to some extent with the following claim made by Jean-Claude Milner. "Something is nonetheless certain: if ethic exists, science has nothing to say about it, and, without doubt, qua science, it can do nothing with it." (Milner, 1995: p. 39, cited in Rado, 2012: p. 84).

The rational way of thinking of modern science has already seeped into our daily lives and has long influenced our life. As Patrick Heelan points out, modern medical science is often accused of reducing patients to a bundle of anatomical sites and physiological processes, each with its own scientific model at the chemical, molecular, or physiological level, with little consideration of the human life in how they affected our lifeworld. When we use medical technology, do we need to consider the meaning behind the case? Or, furthermore, if science is thinking about the thingness of Being, should the meaning of Being be allowed to instruct or qualify scientific thinking? At this point, Heelan argues that such 
unrestricted misuse of scientific terms confuses "the context of science with that of Lifeworld ontology."

Undeniably, medical technology has gradually come to view living life as an object. When we look at humans from a biomedical perspective, they are nothing more than a collection of cells that we can examine and measure in terms of health, unhealthiness, and defects. In such a case, humans become biological bodies and thus comparable objects. As envisioned by Huxley in Brave New World, these objects are then able to be optimized through eugenics. But this does not explain the defects of science itself. My claim is that the inherent objectivity of science is precisely the precondition for its development. Biomedicine cannot progress if it refuses to study the human body because of the dignity of the human being. Or rather, it is precisely this attitude of insisting on objectivity that allows science to emerge. The fundamental problem, then, the problem of thinking, is not science do not think, but humanity, the very subject who should think, has not thought. "What is most considerable shows itself in our considerable age in this: that we are not yet thinking. We are not yet thinking because what is to be thought turns away from the human and not at all only because humans do not sufficiently turn themselves toward [or devote themselves to] what is to be thought." (Heidegger, 2000, p. 134). It is not important that the objectivity of scientific thinking allows science to maintain its purity. What is important is that we do not unthinkingly invade the world of our lives with scientific thinking, impoverishing it.

The challenge we face in contemporary times is how we should deal with a metaphysical world where value is the criterion (perhaps the only criterion) by which being is measured. In this challenge, we should perhaps look at things with an attitude of releasement (Gelassenheit) rather than merely examining the value of beings.

We may find the answer in Jarmusch's film. In Jarmusch's film Paterson, the main character, Paterson, is a bus driver whose life is the same as other bus drivers, driving a set route, returning home after work to walk his dog and then going to the pub for a drink, day after day, year after year. Although it may seem to us that the Paterson's routine is dull and worthless. But even this "worthless" life is, in the eyes of our Paterson, poetic. The breakfast his wife makes in the morning, the milk in the fridge, many ordinary things are full of "meaning". In this meaning-filled life, the meaning of being is no longer determined by the rational world, but is given to us. This is why Heidegger quotes Hölderlin's poem, “...poetically man dwells...". In this way we may be able to escape the grip of scientific and metaphysical thinking and regain the meaning of beings.

\section{Conclusion}

Heidegger's examination of science is, in a nutshell, that science prescribes the progress of revealing as certainty, and the world constituted by Being as a metaphysical grasp of objectivity. He argues that science after Descartes operates from ${ }^{8}$ See Patrick A. Heelan, Carnap and Heidegger (Patrick, 2012). 
the viewpoint that humanity is able to grasp the world as a whole construct through scientific and objective understanding, which in turn strengthens the authority of science and reason through this domination and understanding of the world. The result of this is not only that Being and the meaning of Being are forgotten. We forget this forgettingness while consulting science without limit to establish the world as constituted by Being in the metaphysical sense, i.e. Gestell, and in turn constrain our primitive living world. Although science cannot think, we, who should go to think, forget the essence of thinking and forget Being as Dasein.

\section{Acknowledgements}

I would like to express my very great appreciation to Lilly Gray for her valuable and constructive suggestions on editing of this research work. Her willingness to give her time so generously has been very much appreciated.

\section{Conflicts of Interest}

The author declares no conflicts of interest regarding the publication of this paper.

\section{References}

Belgrano, M. (2021). World and Paradigm in Heidegger and Kuhn. Franciscanum, 63, 1-16. https://doi.org/10.21500/01201468.4716

Dreyfus, H. (2006). Heidegger on the Connection between Nihilism, Art, Technology, and Politics. In C. B. Guignon (Ed.), The Cambridge Companion to Heidegger (pp. 345-372). Cambridge University Press. https://doi.org/10.1017/CCOL0521821363.014

Heidegger, M. (1962). Being and Time. Blackwell Publishers .

Heidegger, M. (1977). The Question Concerning Technology and Other Essays. Harper \& Row.

Heidegger, M. (1985). History of the Concept of Time: Prolegomena. Indiana University Press.

Heidegger, M. (1991). Nietzsche Volume IV: Nihilism. HarperOne.

Heidegger, M. (1992). Parmenides. Indiana University Press.

Heidegger, M. (1993). Basic Writings. Harperone.

Heidegger, M. (2000). Voträge und Aufsätze. Vittorio Klostermann.

Heidegger, M. (2018). The Question Concerning the Thing: On Kant's Doctrine of the Transcendental Principles. Rowman \& Littlefield.

Kuhn, T. S. (1996). The Structure of Scientific Revolutions. The University of Chicago Press. https://doi.org/10.7208/chicago/9780226458106.001.0001

Milner, J.-C. (1995). L'oeuvre claire. Lacan, la science, la philosophie. Le Seuil.

Patrick, H. A. (2012). Carnap and Heidegger. In G. Trish (Ed.), Heidegger on Science (pp: 113-130). State University of New York Press.

Rado, R. (2012). Does Science Think? Filozofski vestnik, 33, 77-93.

Wendland, A. J. (2018). Heidegger vs. Kuhn: Does Science Think? In A. J. Wendland, C. Merwin, \& C. Hadjioannou (Eds.), Heidegger on Technology (pp. 282-298). Routledge. 